\title{
An Ultrastructural Study of Ingestion and Digestion in Tetrahymena pyriformis*
}

\author{
ALFRED M. ELLIOTT and GRETCHEN L. CLEMMONS $\dagger$
}

Department of Zoology, The University of Michigan, Ann Arbor

SYNOPSIS. When the structures involved in digestive events in $T$. pyriformis are examined at the electron microscope level, some information is added to that long known from light microscopy. The food trapping mechanism consists of the three membranelles, undulating membrane, oral ribs, and a "valve" apparently closing the opening to the cytopharynx. Both of the latter structures are supported by microtubules. Fibers extend internally from the cytopharynx and are closely associated with the food vacuole as it forms.

Clear vacuoles resembling pinocytic vacuoles appear to arise from differentiated areas of the pellicle and plasma membrane. These vacuoles may fuse with primary lysosomes. Hydrolases are thus con-

$\mathrm{T}^{\mathrm{H}}$ HERE is a vast literature on ingestion, digestion, and egestion in protozoa $(14,19)$. Among ciliates, Paramecium has been most frequently studied $(13,18,22,26,32)$ and recently some attention has been given to Tetrahymena pyriformis $(21,27,28)$. The localization of hydrolases in food vacuoles, using cytochemical technics $(1,15)$, and the process of digestion in these vacuoles have been established $(21,22)$. Even so, little effort has been made to correlate these digestive events with ultrastructure. This study was undertaken to follow digestion in $T$. pyriformis from the time food enters the cell until egestion takes place, employing cytochemical technics at the electron microscope level.

\section{MATERIALS AND METHODS}

Strain $\mathrm{E}$ of $T$. pyriformis was used throughout this investigation. The ciliates were grown axenically in $500 \mathrm{ml}$ Erlenmeyer flasks in $2 \%$ proteose-peptone (Difco Laboratories, Detroit) supplemented with $0.5 \%$ glucose, $0.1 \%$ liver extract and a mineral salt mixture. The osmolarity of the media was 100 milliosomols which is essentially the same as a brei prepared from soft pellets of ciliates. The determinations were made with a Fiske Osmometer Mark III. The ciliates used were in logarithmic (48-72 hr) growth phase, incubated at $25 \mathrm{C}$. Each experiment was performed with cells that had been starved for several hours in a buffered salt solution at 100 milliosomols. They were then fed dilute suspensions of India ink, colloidal gold (Harleco), and bacteria. After feeding intervals of 15 $\min , 0.5 \mathrm{hr}, 1 \mathrm{hr}$ and $2 \mathrm{hr}$, they were concentrated by centrifugation into a soft pellet and fixed for $20 \mathrm{~min}$ in $3 \%$ sodium cacodylatebuffered glutaraldehyde ( $\mathrm{pH} 7.2$ ). Then they were washed overnight in $0.1 \mathrm{M}$ sodium cacodylate ( $\mathrm{pH} 7.2$ ) and post-fixed for 15 minutes in 1 per cent $\mathrm{OsO}_{4}$ ( $\mathrm{pH} 7.4$ ) buffered with 0.14 veronal acetate containing $45 \mathrm{mg}$ of sucrose per $\mathrm{ml}$. Dehydration and embedding in Epon 812 were carried out according to the method of Luft(16). The blocks were polymerized for 3 days at graded temperatures $(37-60 \mathrm{C})$, sectioned with a Porter-Blum MT2 microtome and examined in an RCA EMU $3 E$.

For acid phosphatase localization the same fixation procedure was used. The cells were then incubated for $30 \mathrm{~min}$ at $37 \mathrm{C}$ in sodium beta glycerophosphate medium at $\mathrm{pH} 5.0$, rinsed in $2 \%$ acetic acid for less than 30 seconds, and washed in $0.05 \mathrm{M}$ acetate buffer ( $\mathrm{pH}$ 5.0) according to Gomori(11). The acetic acid rinse removed most

* This investigation was supported by a Research Grant A1 01416-13 from the National Institute of Allergy and Infectious Diseases, N.I.H. U.S.P.H.S.

† Present address: Pharmacological Animal Laboratory, Food and Drug Administration, Beltsville, Maryland. tributed to the pinocytic vacuoles which may then fuse with food vacuoles. When first formed food vacuoles contain no hydrolases but may acquire them directly, from primary lysosomes or from pinocytic vacuoles. Digestion proceeds to completion in the food vacuole, at which time soluble food products are released to the cytoplasm. Undigested materials are lost through the cytopyge. In stationary growth phase cells autophagic vacuoles form containing mitochondria and other cellular particulates. Such vacuoles probably contain hydrolases when formed and they may receive others by fusion with primary lysosomes.

of the deposits in the macronucleus and mitochondria. The cells were post-fixed for $20 \mathrm{~min}$ in $1 \% \mathrm{OsO}_{4}$ containing $7.5 \%$ sucrose. Dehydration and embedding procedures followed those described above. Controls were maintained without glycerophosphate substrate. The enzymes were also destroyed by exposing the cells to ultraviolet light after fixation and before incubation in Gomori medium.

\section{RESULTS}

\section{The Buccal Cavity}

Bacteriophagous ciliates possess a complex feeding apparatus, and $T$. pyriformis is no exception. Its structure has been well documented from light microscope studies $(3,9)$. At the electron microscope level additional structures can be seen. The undulating membrane arises from approximately 20 kinetosomes arranged in a single row lying in the right wall of the buccal cavity (Fig. 1). A supporting row of non-ciliated kinetosomes parallels the row bearing cilia. These structures have been seen but not illustrated with micrographs in this study. Lying in the immediate vicinity of these kinetosomes and lining a portion of the right wall of the buccal cavity are the oral ribs (Figs. 1, 2). Each rib is supported by dense microtubules approximately $200 \AA$ in diameter arranged in 2 groups; one group has 2 and the other has 4 or 5 microtubules (Fig. 5). They continue internally to the vacuole, forming the wall of the cytopharynx (Fig. 2). There are no ribs in this region, but farther on 2 pointed projections extend into the food vacuole (Fig. 2). Opposite the oral ribs in the cytopharynx the left wall of the buccal cavity is modified to form a "valve-like" structure whose internal face interdigitates with the oral ribs in that area (Figs. 2, 3, 5). This structure is supported by microtubules resembling those supporting the oral ribs (Figs. 3,5 ). The cytoplasmic matrix in the region of the valve lacks density and in some micrographs appears finely fibrous (Fig. 4). Internal to the valve and lying on the left side of the food vacuole one frequently observes fibers extending from the base of the valve approximately $1 / 3$ way around the vacuole (Figs. 1, 2, 4). Their dense structure and large size $(1000 \AA)$ suggest that they are supporting structures.

Kinetosomes that give rise to the 3 membranelles $\left(M_{1}\right.$, 
$\mathbf{M}_{2}, \mathrm{M}_{3}$ ) lie beneath the left wall of the buccal cavity (Fig. 1). They all are composed of 3 rows of cilia. $\mathbf{M}_{1}$ and $M_{2}$ membranelles have approximately 10 cilia. $M_{3}$ is shorter with fewer cilia. The cilia of the membranelles are considerably longer than those covering the body.

In the vicinity of the cytopharynx numerous double-

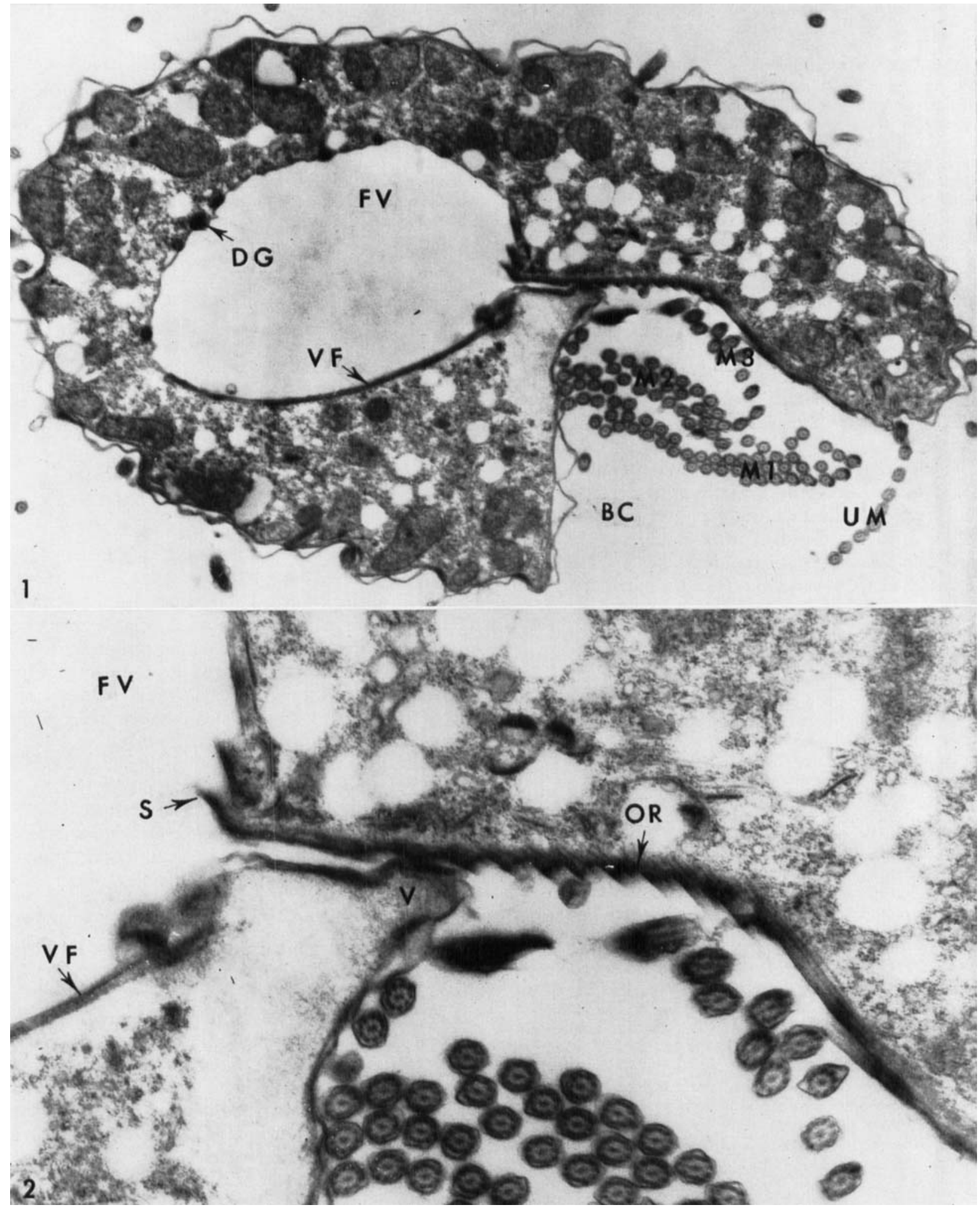

All figures are electron micrographs except where indicated.

Fig. 1. A tangential section of the buccal cavity (BC) showing a distended food vacuole (FV), membranelles $\left(\mathbf{M}_{\mathbf{1}}, \mathbf{M}_{\mathbf{2}}, \mathbf{M}_{\mathbf{3}}\right)$, vacuole fibers (VF) and undulating membrane (UM). Dense granules (DG) adhere to the vacuole membrane. $\times 3500$.
Fig. 2. An enlargement of a portion of Figure 1 showing the oral ribs (OR), the valve (V), spines (S) and vacuole fibers (VF). Note the less dense area under the valve. A portion of the food vacuole $(\mathrm{FV})$ is included. $\times 8000$. 
membraned vesicles occur (Figs. 3, 4). Their contents resemble the cytoplasmic matrix. Similar vesicles were de- scribed by Miller and Stone(17) in T. patula. Since they appear in close proximity to the newly forming vacuole
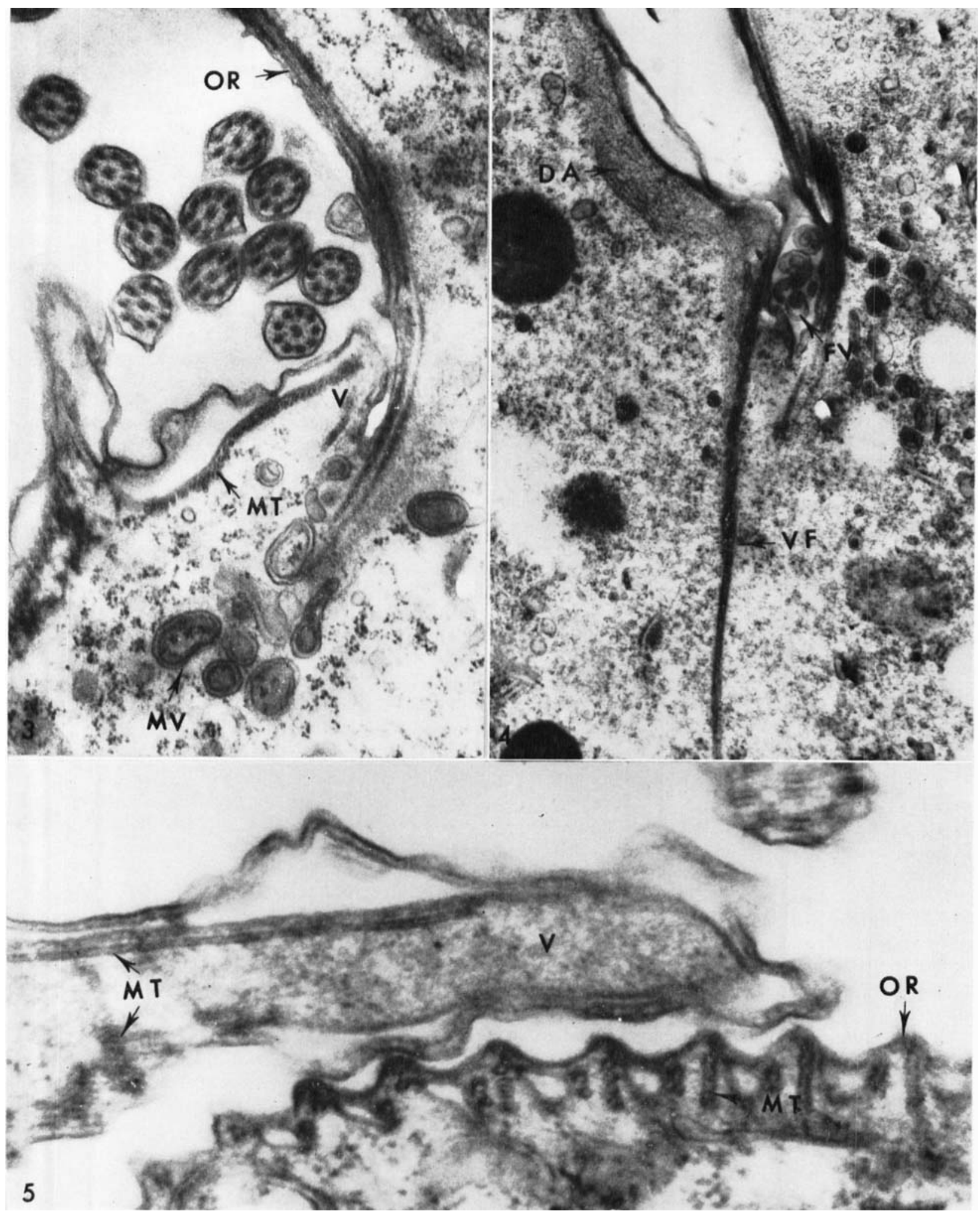

Fig. 3. A section through the cytopharynx showing the valve (V) with its microtubules (MT). Note the double membraned vesicles (MV) containing material similar to the cytoplasmic matrix. The terminal portion of the oral ribs $(O R)$ is included. $\times 14,500$.

Fig. 4. This section through the cytopharynx shows a food vacuole $(F V)$ as it begins to form. Note the vacuole fibers (VF). The dif- ferentiated area (DA) is finely fibrous. $\times 7500$.

Fig. 5. A high power view of the valve (V). Note the supporting microtubules (MT) in longitudinal section in the valve and in cross section in the oral ribs. The outer membranes of the valve interdigitate with a few of the oral ribs (OR). $\times 30,000$. 
(Fig. 4), both inside and outside, they may contribute structural material to the vacuolar membrane.

No effort was made in this study to determine the relationship to cytoplasmic organelles of the numerous fibers seen in micrographs.

\section{The Food Vacuole}

When $T$. pyriformis is suspended with bacteria (Aerobacter aerogenes) or in proteose-peptone, food vacuoles can be readily seen under the phase-contrast microscope. They can be visualized much better by placing the ciliates in dilute suspensions of India ink alone or a mixture of India ink and bacteria. Whereas no critical time sequence studies of food vacuole formation were made, some qualitative observations were recorded. Müller and Törö(22) described 4 stages (I-IV) in Paramecium multimicronucleatum. Similar stages probably occur in $T$. pyriformis, although our study is not as precise as that of these authors so that we can only approximate the stages.

When starved cells (24 hours) are suspended in the mixture of bacteria and India ink, uniformly large food vacuoles form in five minutes. Within 15 minutes the cytoplasm contains many vacuoles (Fig. 6). These vacuoles are smoothly round, showing patches of India ink and evenly distributed bacteria. They are in stage $I$ and, as shown below, contain no acid phosphatase. They retain this structure for about 30 minutes. Then the bacteria seem to become compacted, leaving a clear space between the bacterial mass and the membrane forming a "halo" (stage II). Later the vacuole becomes more dense (stage III), which probably results from the condensing of the inert India ink carbon particles. During stage IV the vacuoles are small, black and spherical. Presumably they contain only the indigestible carbon particles (India ink). These vacuoles can be seen to leave the ciliate through the cytopyge. This is a rapid process which we have been unable to photograph.

Ciliates suspended in India ink alone form small, extremely dense vacuoles which are more numerous than when the ciliates are fed the bacterial mixture (Fig. 7). No "halo" is observed in any of these vacuoles and their contents are egested in essentially the same form as when they were pinched off from the cytopharynx. These carbon-containing fecal pellets are without membranes (Fig. 15). Perhaps the vacuole membrane everts as it delivers its contents through the cytopyge.

The ultrastructure of ciliates which have been fed bacteria or proteose-peptone provides additional information about the events occurring during digestion. When the ciliates have been fed bacteria for $2 \mathrm{hr}$, the food vacuoles can be seen in all stages of digestion (Fig. 8). The bacteria in a recently formed vacuole (stage I) are loosely packed and can easily be distinguished from older vacuoles.

Within 30 minutes bacterial disintegration begins, resulting in fragments which aggregate and shrink slightly, leaving a space between the bacterial mass and the membrane (Fig. 10). Clear vesicles occupy this space. The shrinking of the food mass continues, resulting in the "halo" effect observed in light micrographs (Fig. 6). As digestion con- tinues the matrix of the bacteria becomes soluble, and the discrete bacterial mass breaks down, leaving numerous membranes and other debris (Fig. 11). Tiny vesicles appear on the outside membranes of such vacuoles, suggesting that soluble end-products are being released to the cytoplasm by pinocytosis.

When cells are fed colloidal gold alone, vacuoles form normally (Fig. 12). However, if the ciliates are offered a mixture of colloidal gold and bacteria, they select the bacteria to the exclusion of the gold (Fig. 13). They seem to be remarkably efficient in discriminating between organic matter and inert material. However, when fed a mixture of India ink and bacteria, they are not so efficient as demonstrated in Fig. 11, in which some carbon particles can be detected.

When cells are grown in proteose-peptone, numerous clear vacuoles appear (Fig. 9). No changes can be observed during digestion. Occasionally a vacuole will contain crystalline material which is apparently concentrated from a precipitate in the medium. Such proteose-peptone vacuoles often coalesce with one another as shown in Fig. 14.

In order to follow the hydrolysis of food in the vacuoles, bacteria- and proteose-peptone-fed ciliates were treated for the identification of acid phosphatase. Shortly after formation, the food vacuoles contain little or no enzyme. The slight reaction seen in those containing bacteria is localized in the bacteria themselves (Fig. 16). There is no reaction in the vacuoles containing proteose-peptone (Fig. 17). In both instances pinocytic vacuoles (see below), heavily laden with acid phosphatase, lie in the immediate vicinity of the food vacuoles, suggesting that they may be about to fuse with them.

A few minutes later the bacteria-containing vacuoles show dense reaction products, indicating high concentrations of acid phosphatase (Fig. 18). The bacteria are partially digested in such vacuoles. At a later time only remnants of bacterial walls remain (Fig. 19). Small amounts of the enzyme appear to adhere to these membranes. The food vacuole membrane is highly irregular. The same is true of vacuoles containing proteose-peptone (Fig. 20). About 30 minutes after they have formed they contain high concentrations of acid phosphatase distributed throughout the vacuole. After $2 \mathrm{hr}$ the enzyme reaction products accumulate at the vacuole membrane and have diminished in quantity (Fig. 21). Such vacuoles show extensive irregularities in the membrane.

Clear vacuoles appear near the plasma membrane and are often seen in the vicinity of protrichocysts as shown in Fig. 22. Since these vacuoles are empty in both $\mathrm{OsO}_{4}$ and glutaraldehyde-fixed cells they are interpreted to be pinocytic vacuoles. Primary lysosomes containing acid phosphatase reaction products frequently lie close to these vacuoles (Figs. 23, 24). Other larger vacuoles, rich in acid phosphatase, appear in the vicinity of the food vacuoles (Figs. 24, 25). These reactive vacuoles are smaller than food vacuoles and larger than pinocytic vacuoles. Their clear background, studded with dense reaction products, also suggests that they are pinocytic vacuoles which have received enzymes from the primary lysosomes. 


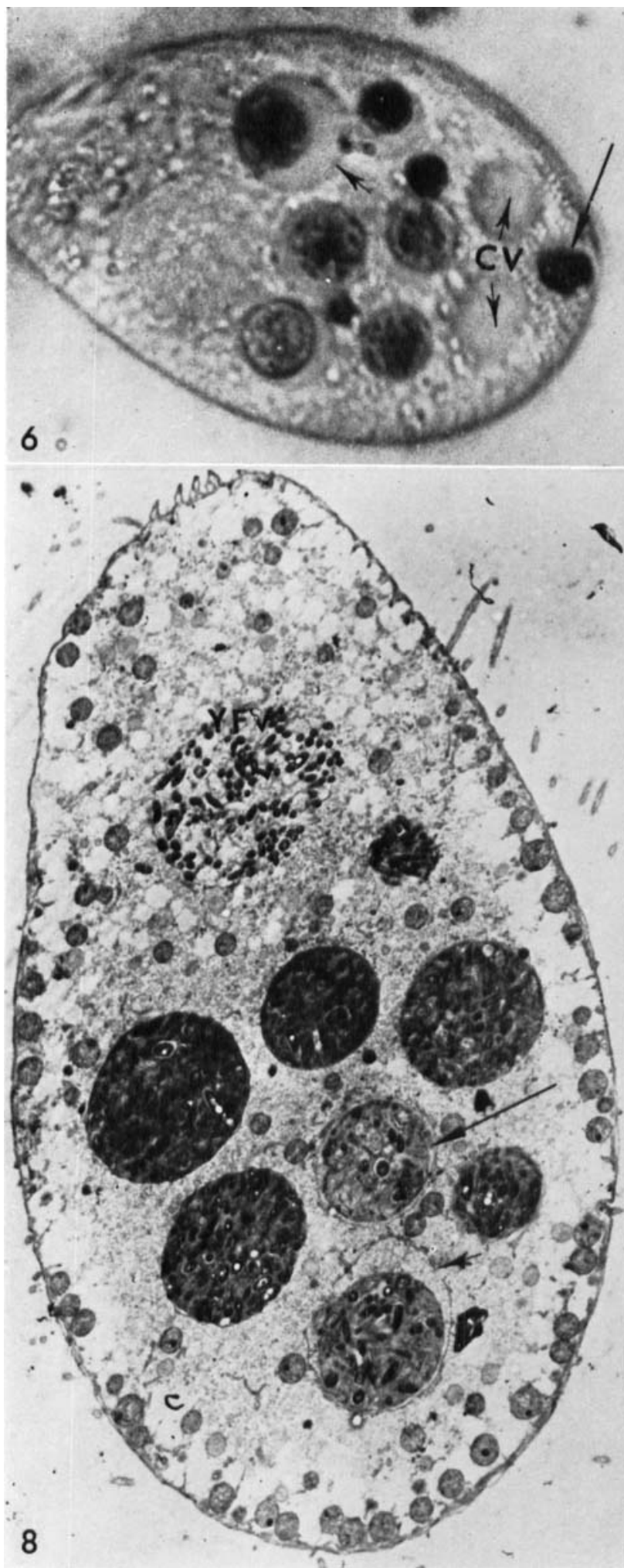

Figs. 6 and 7 are phase-contrast photomicrographs of living ciliates. Fig. 6. This cell fed on a suspension of bacteria and India ink. The vacuoles are large and an occasional one shows a space between the bacterial mass and the membrane (short arrow). A vacuole about to be egested is dense and lies in the region of the cytopyge (long arrow). This ciliate has 2 contractile vacuoles (CV) which is uncommon. $\times 1300$.

Fig. 7. This ciliate was suspended in dilute India ink. Note the numerous small vacuoles. One has just egested (arrow) and another is about to. $\times 1300$.

Fig. 8. A longitudinal section of a whole ciliate fed bacteria. The
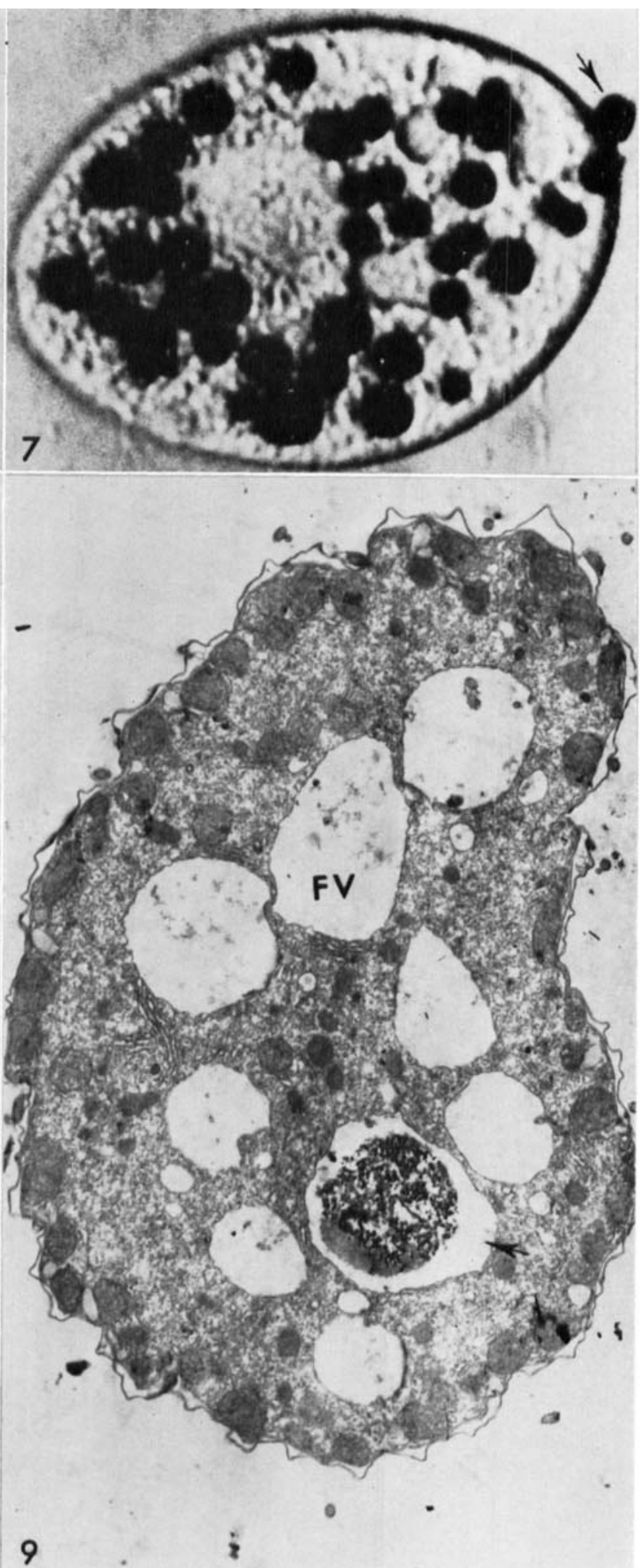

food vacuoles are in various stages of digestion. The bacteria in the young food vacuole (YFV) are loosely packed. As digestion proceeds they become compacted and dense. The vacuole labelled with the short arrow shows the "halo" observed in the light microscope (Fig. $6)$. Digestion is nearly completed in the vacuole labelled with the long arrow. $\times 3000$.

Fig. 9. This cell is comparable to the one in Figure 8 except it has been feeding on proteose-peptone. All the vacuoles (FV) are clear except one (arrow) which contains debris concentrated from the medium. $\times 3000$. 

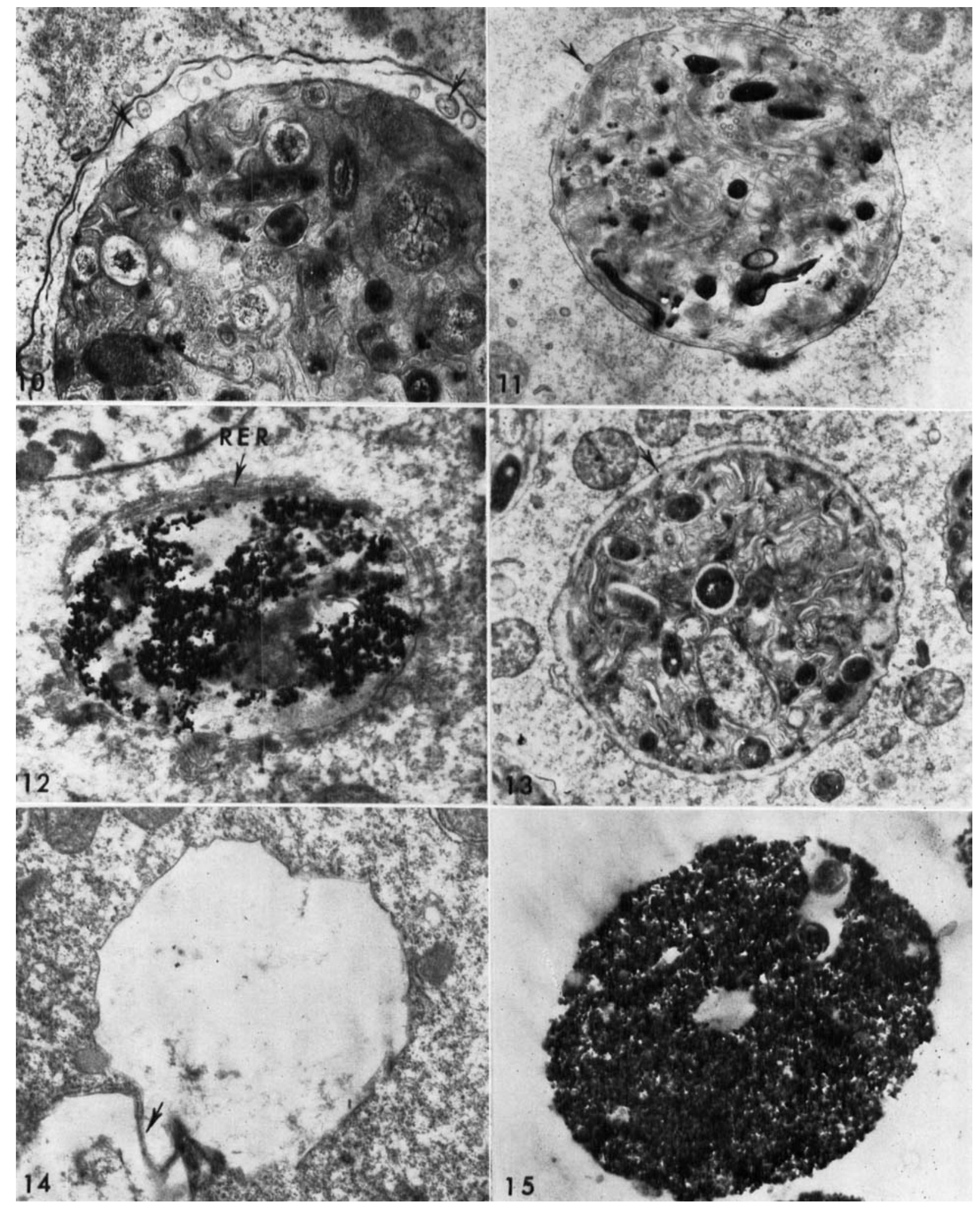

Fig. 10. An enlarged view of a food vacuole containing bacteria. Many bacteria are broken indicating that digestion is underway. The bacterial mass has begun to compact leaving a space between it and the membrane. Small vesicles (arrows) appear in this space. $\times 12,500$.

Fig. 11. This older food vacuole is from a cell fed a mixture of India ink and bacteria. Note that some India ink (dense particles) was taken in by the ciliate. Digestion is complete. Tiny vesicles (arrow) seem to be coming out of the vacuole. $\times 12,000$.

Fig. 12. This vacuole is from a cell fed colloidal gold which appears as dense particles. The whorls of rough endoplasmic reticulum (RER)

are often seen around food vacuoles. $\times 12,000$.

Fig. 13. A vacuole from a cell fed a mixture of colloidal gold and bacteria. Note that only an occasional gold particle can be seen (arrow). The ciliate is able to efficiently separate gold and bacteria. $\times 12,000$.

Fig. 14. A proteose-peptone vacuole coalescing with another one (arrow). This frequently happens. $\times 12,000$.

Fig. 15. This is a fecal pellet egested from a cell fed India ink. Note that it has no membrane. $\times 12,000$. 
There is no confusion between primary lysosomes and newly formed pinocytic vacuoles; the former always have a uniform, slightly dense matrix, whereas the latter are empty. Moreover, primary lysosomes have acid phosphatase reaction products whereas recently formed pinocytic vacuoles do not. Protrichocysts (Figs. 24, 25) frequently resemble primary lysosomes in both size and density, particularly during early stages of their development. Mature protrichocysts are more elongate ovals and are clearly distinguished from primary lysosomes. Moreover, these structures do not contain acid phosphatase reaction products.

The lumina of the RER closely associated with mitochondria often contain acid phosphatase reaction products (Fig. 25), suggesting that hydrolases are synthesized by the attached ribosomes. Reaction products are also seen in the perinuclear space of the macronucleus.

When digestion is complete, membranes of the food vacuoles, now defined as residual vacuoles in metazoan cells(4), are irregular and frequently have finger-like blebs (Fig. 26). The acid phosphatase reaction products are usually concentrated at the periphery of the inner wall of the vacuole and are carried into the blebs. These may pinch off and deposit their contents into the cytoplasm. Small bits of dense material are often seen in the cytoplasm, but it is impossible to determine their origin.

\section{DISCUSSION}

Food vacuole formation. The food trapping mechanism in $T$. pyriformis is a complex structure, as it is in other bacteriophagous ciliates. The membranelles seem to have the same structure as described for $T$. patula by Miller and Stone(17). Each is composed of 3 rows of cilia which are longer than body cilia. $M_{3}$ has fewer cilia than $M_{1}$ and $\mathbf{M}_{2}$. The structure of the undulating membrane also seems to be identical to that of $T$. patula. It is composed of a single row of ciliated kinetosomes and 1 row without cilia. As suggested by Miller and Stone(17), the latter may offer support for the undulating membrane.

The other buccal organelles consist of the oral ribs and the "valve." As pointed out by Miller and Stone(17), the oral ribs are differentiated pellicle and apparently have no relationship with kinetosomes. The fact that the ribs are underlaid with thick-walled microtubules in a regular pattern suggests that they offer support to the buccal cavity wall. Such tubules have a supporting function in many protozoa(25). Tubules of similar structure continue into the vacuole, terminating in sharp spines. What function, beyond support, these structures possess is obscure.

The "valve" or "flap" arises from the left part of the floor of the buccal cavity and its free end lies in close apposition to the innermost portion of the oral ribs. In all sections observed, it lies in this position regardless of whether the vacuole is filling or is non-existent. The valve is supported by microtubules, which suggest that it is relatively rigid. It could function in food selection and food vacuole formation. Obviously conclusions about its function from morphological studies must be speculative.

When the vacuole begins to form, a double unit membrane can be seen closing the cytopharynx. Double-mem- braned vesicles appear inside. They are similar to those in the cytoplasm but do not contain material resembling that of the cytoplasmic matrix. These may be involved in vacuole membrane formation or they could simply be ingested material. As the vacuole fills, it increases in diameter and seems to slide along the adjacent fibers. When fully distended, it extends beyond the fibers. Perhaps these fibers function in directing the vacuole into the deeper cytoplasm before it is released. They resemble the postesophageal fibers in Paramecium(14).

Dense granules adhere to the vacuole as it enlarges. These may be similar to those noted in newly formed vacuoles in Paramecium aurelia $(13,26)$. Müller (personal communication) finds no acid phosphatase in these granules in $T$. pyriformis. We have confirmed this observation. This probably means that these granules are not associated with digestive events. Their function is obscure.

Digestive events. Digestion in protozoa, as in all cells, involves the synthesis of hydrolases and their subsequent transport to sites of action. DeDuve and his associates (4) were the first to describe a group of subcellular particles, rich in acid hydrolases, which they defined as lysosomes. These observations were based on biochemical evidence from mammalian cells. According to DeDuve (5), lysosomes fall into two major groups: 1. Primary lysosomes are sacs of hydrolytic enzymes prior to their involvement in digestive events. 2. Secondary lysosomes are vacuoles of several types (digestive or food vacuoles, of ten called phagosomes; autophagic vacuoles or cytolysomes; and residual vacuoles), all of which contain acid hydrolases and material in various stages of digestion.

Novikoff and his associates $(23,24)$ have suggested that in mammalian cells hydrolytic enzymes are synthesized at the ribosomes, gain access to the RER, make their way via the smooth endoplasmic reticulum (SER) and the Golgi apparatus into the Golgi vesicles, and are ultimately transported to sites of action, namely, autophagic vacuoles or food vacuoles. In protozoa no such sequence of events has been documented, although a number of studies have given evidence that a similar process may take place.

Acid phosphatases have been localized in protozoa by a number of investigators $(1,2,10,15,19,27,29,31)$. Müller and his associates $(18,19,20,21,22)$ have concentrated their attention on Paramecium and Tetrahymena, where they have localized acid phosphatase in food vacuoles at the light microscope level. In earlier reports $(7,8)$ we tentatively identified certain oval slightly dense vacuoles (0.5$1.0 \mu$ ) in $T$. pyriformis as lysosomes without cytochemical proof. More recently (6) acid phosphatase reaction products have been found in these vacuoles, hence they have been defined as primary lysosomes(4). Acid phosphatases have also been localized in autophagic vacuoles as well as food vacuoles.

Allen et al.(1) have separated a number of acid phosphatases from T. pyriformis (variety 1) using electrophoretic technics. By comparing zymograms of cells grown in different media they have shown quantitative and qualitative differences in the enzymes. Cells cultured with bacteria or proteose-peptone contain more kinds of acid phos- 


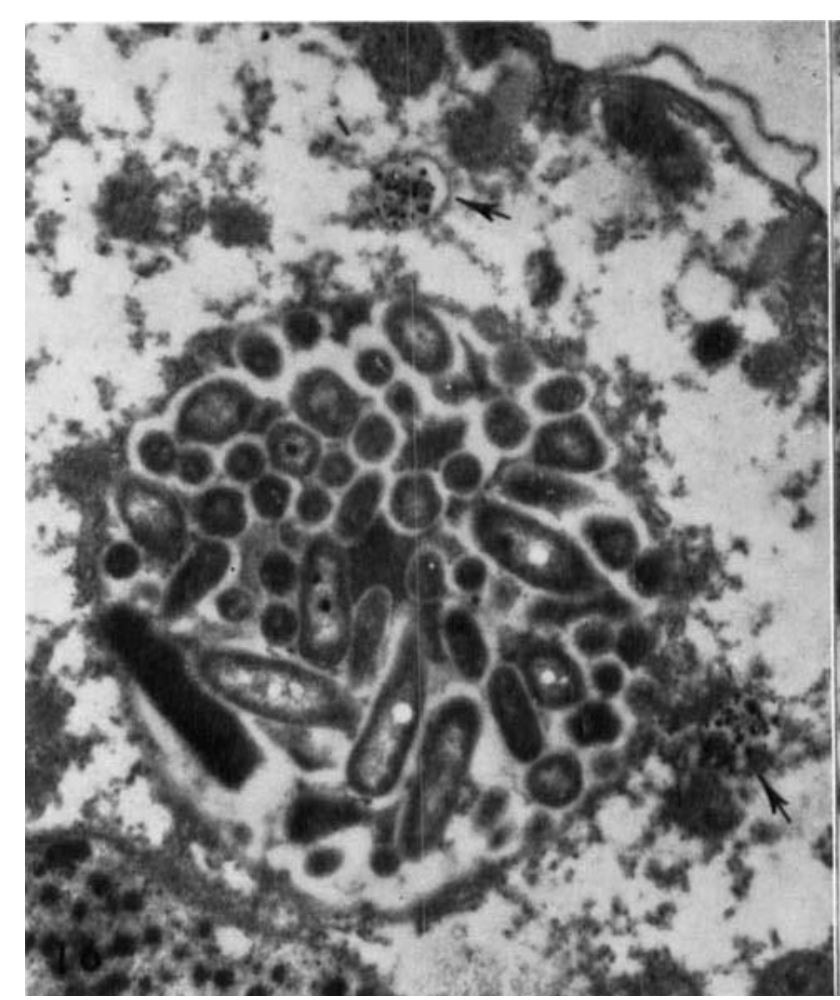

Figures 16-19 and 21-25 include cells incubated in Gomori's medium for the localization of acid phosphatase.

Fig. 16. A young vacuole from a cell fed bacteria. Except for a slight reaction in a few bacteria the vacuole contains no acid phosphatase. Reactive pinocytic vacuoles (arrows) lie nearby. Pre-

phatases than those grown in chemically defined media. The phosphatases vary in quantity as well. Moreover, most enzymes are associated with the fraction of large particles (P-1), but one, quite different from the others, was found in the microsomal fraction (P-3), suggesting it may be localized in the RER. The ultrastructural localization of acid phosphatase in the present study supports these observations. Primary lysosomes, food vacuoles, and autophagic vacuoles would be included in the P-1 fraction and they are rich in acid phosphatase. In this study deposits of reaction products were localized in the lumina of the RER (Fig. 25). This enzyme would be included in the P-3 fraction. However, it may not be the same enzyme identified by Allen et al.(1) in the P-3 fraction, since their enzyme did not hydrolyze sodium beta glycerophosphate. These authors also showed that the quantity of enzymes was much greater in those cells which were forming food vacuoles, i.e., those that were ingesting food that required hydrolases for degradation. Cells absorbing degraded nutrients (amino acids, vitamins, etc.), as is the case in the chemically defined medium, form few if any food vacuoles (28) and consequently require few hydrolases. Apparently food vacuoles stimulate the synthesis of hydrolytic enzymes.

When the food vacuole is first formed, it contains no acid phosphatase except that which might have been included with the food. A slight amount of acid phosphatase reaction products is seen in those cells which have been feeding on bacteria, but none appears in the vacuoles of ciliates that have ingested proteose-peptone. Apparently the enzyme in the vacuoles containing bacteria comes from

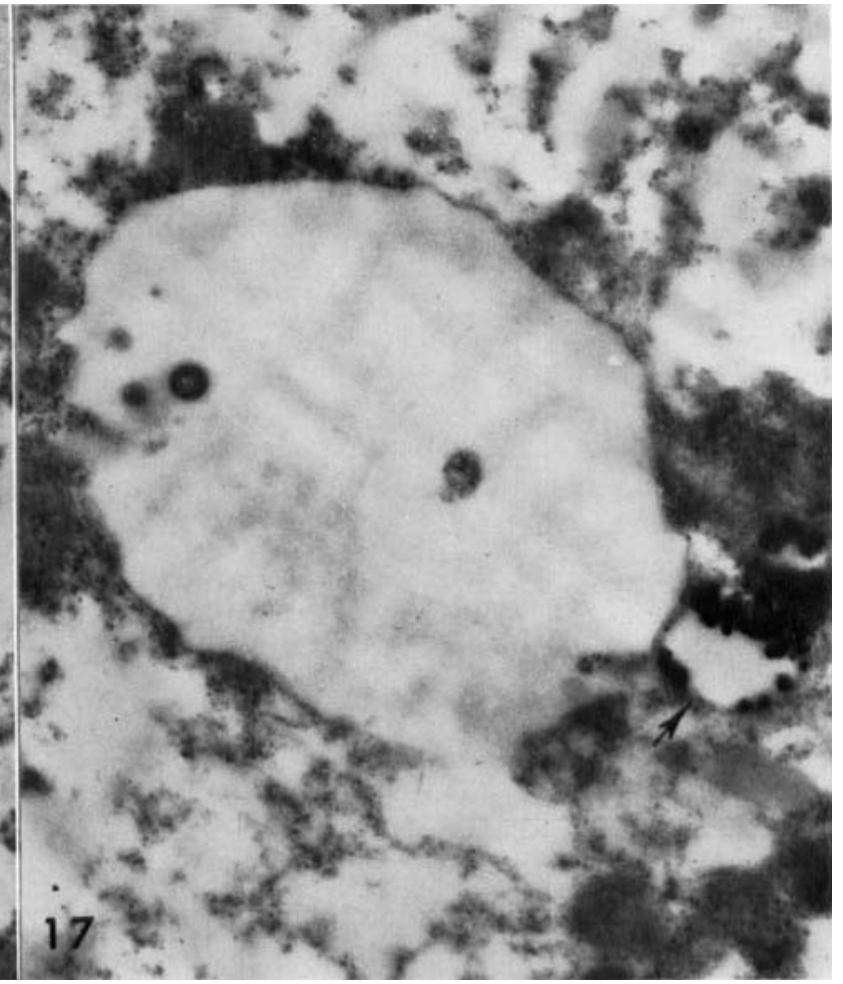

sumably they will fuse with the food vacuole. $\times 12,000$.

Fig. 17. A young vacuole from a cell fed proteose-peptone which contains no acid phosphatase. A pinocytic vacuole (arrow) lies close to the food vacuole membrane suggesting that it is about to fuse with the food vacuole. $\times 12,000$.

these microorganisms. This observation is in agreement with that made by Müller et al.(21), working at the light microscope level. They found in both $T$. pyriformis and Paramecium multimicronucleatum that when the cells are fed inert polystyrene latex particles, no acid phosphatase appears in the newly formed vacuoles (stage I). Later stages II and III), heavy deposits of reaction products are located at the periphery of the vacuoles. These observations are borne out at the ultrastructural level of our study. Both suggest that acid phosphatase gains access to the food vacuole shortly after it is formed. Just how this happens is conjectural, but micrographs presented in our study suggest that fusion of primary lysosomes with both pinocytic vacuoles and food vacuoles may occur. Such fusion has been documented in mammalian cells. Gordon et al.(12) have shown in strain L (Earle) fibroblasts that fusion of primary lysosomes (proto-lysosomes) with phago-lysosomes (digestive vacuoles) and food vacuoles (phagosomes) takes place. They fed cells DNA-protein coacervates containing colloidal gold. Based on this evidence it is not unreasonable to assume that the same process occurs in $T$. pyriformis.

The pathway of hydrolytic enzymes from their origin to their sites of action apparently varies in different ciliates. Acid phosphatase reaction products appear in the lumina of the RER (Fig. 25) in T. pyriformis, suggesting that hydrolases arise there. This is also true of Campanella umbellaria $(2,10)$. In the latter organism, however, hydrolases gain access directly to pinocytic vacuoles when they pinch off from the newly formed food vacuole, without the formation of primary lysosomes. Primary lysosomes apparently 


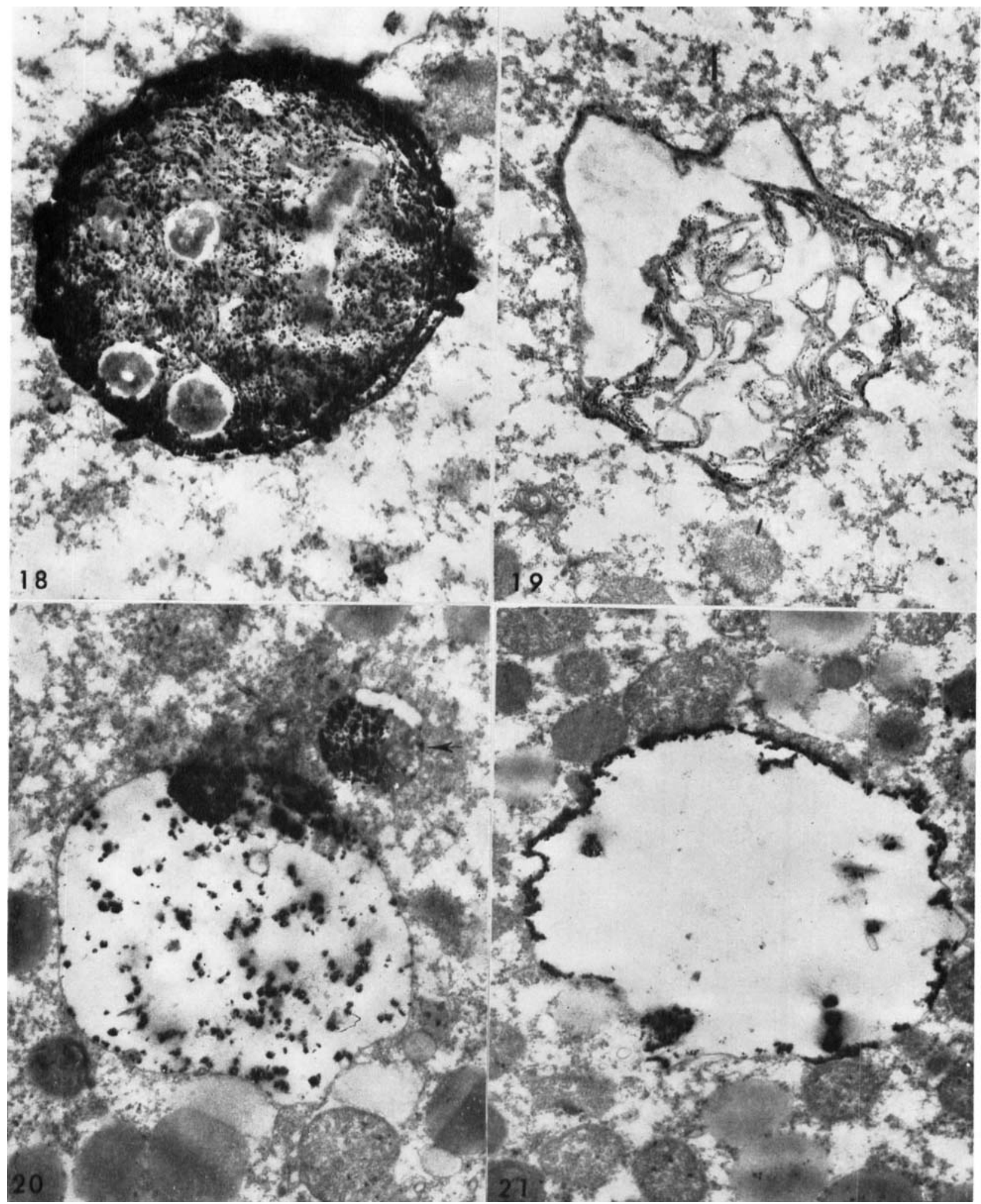

Fig. 18. The bacteria in this food vacuole are partially digested. Note the heavy reaction products indicating high concentration of acid phosphatase. $\times 12,000$.

Fig. 19. Digestion is essentially complete in this food vacuole. Only remnants of the bacteria remain and very little acid phosphatase is present. $\times 12,000$.

Fig. 20. A recently formed food vacuole from a cell fed proteosepeptone. Acid phosphatase is abundant and distributed throughout the vacuole. Note another small reactive food vacuole (arrow) which may fuse with the larger one. $\times 12,000$.

Fig. 21. An old food vacuole from a cell fed proteose-peptone. Note the peripherally located acid phosphatase reaction products and the irregularity (blebbing) of the membrane. There is less of the reaction products in this vacuole when compared to Figure 20, suggesting that some acid phosphatase has been lost to the cytoplasm. $\times 12,000$. 
form in $T$. pyriformis and then fuse with food vacuoles and possibly autophagic vacuoles.
It has been known for some time that $T$. pyriformis takes in small particles through the plasma membrane, as well as

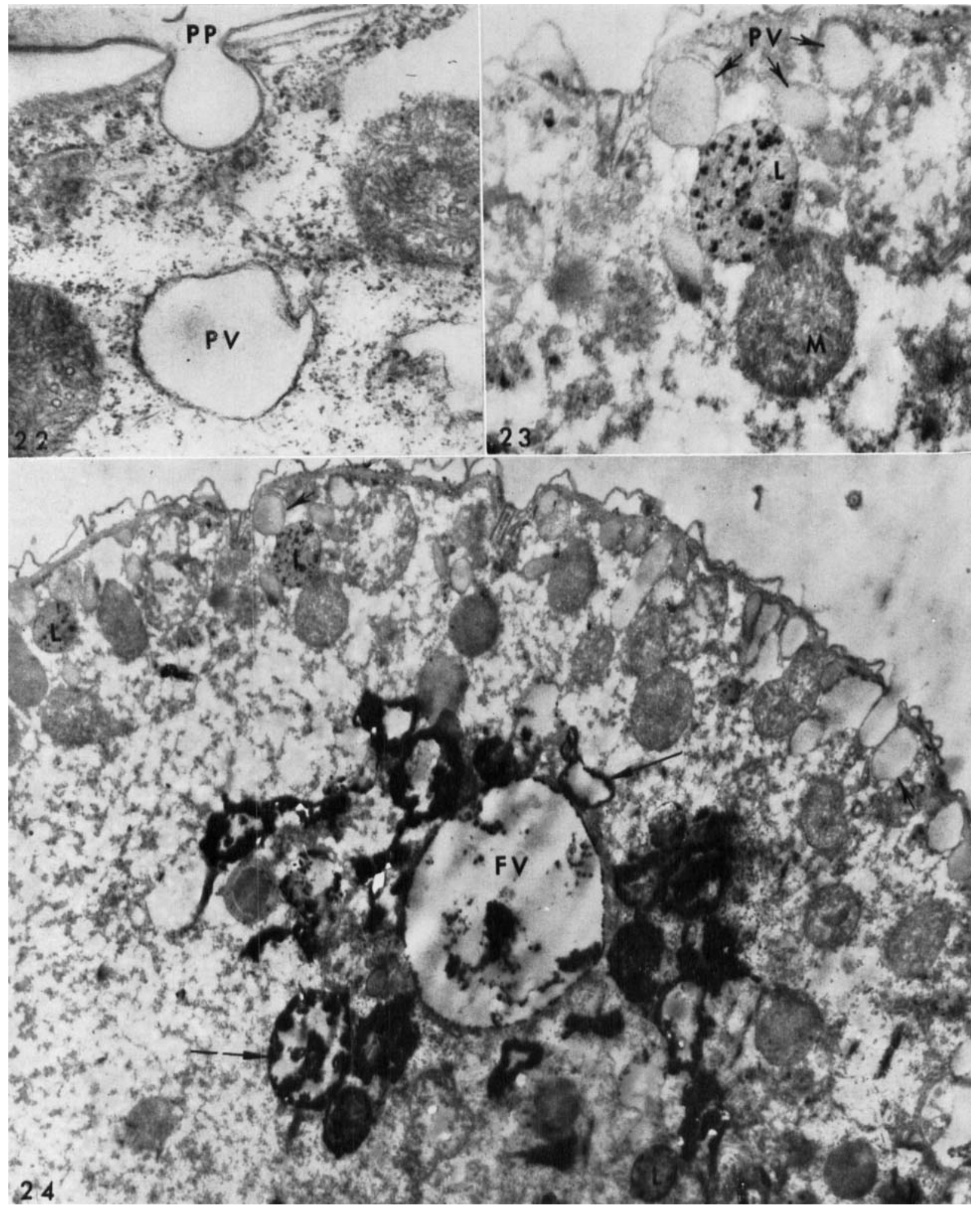

Fig. 22. This is from an $\mathrm{OsO}_{4}$-fixed cell showing the protrichocyst pore (PP) and a pinocytic vacuole (PV) lying close by. $\times 18,000$.

Fig. 23. The relationship of a primary lysosome (L) mitochondrion (M), and a pinocytic vacuole (PV) is shown in this micrograph. The close proximity suggests that they may fuse. This is an enlargement of a portion of Figure 24 . $\times 14,000$.

Fig. 24. A low magnification micrograph showing the general rela- tionship of primary lysosomes (L), pinocytic vacuoles (short arrows), protrichocyst (P), and a food vacuole (FV) in a ciliate fed proteosepeptone. Note the peripheral location of the primary lysosomes and the inactive pinocytic vacuoles. Pinocytic vacuoles (long arrows), close to the food vacuole, are reactive whereas those farther away are not. This suggests that the food vacuole gains its enzymes from reactive pinocytic vacuoles. $\times 7200$. 


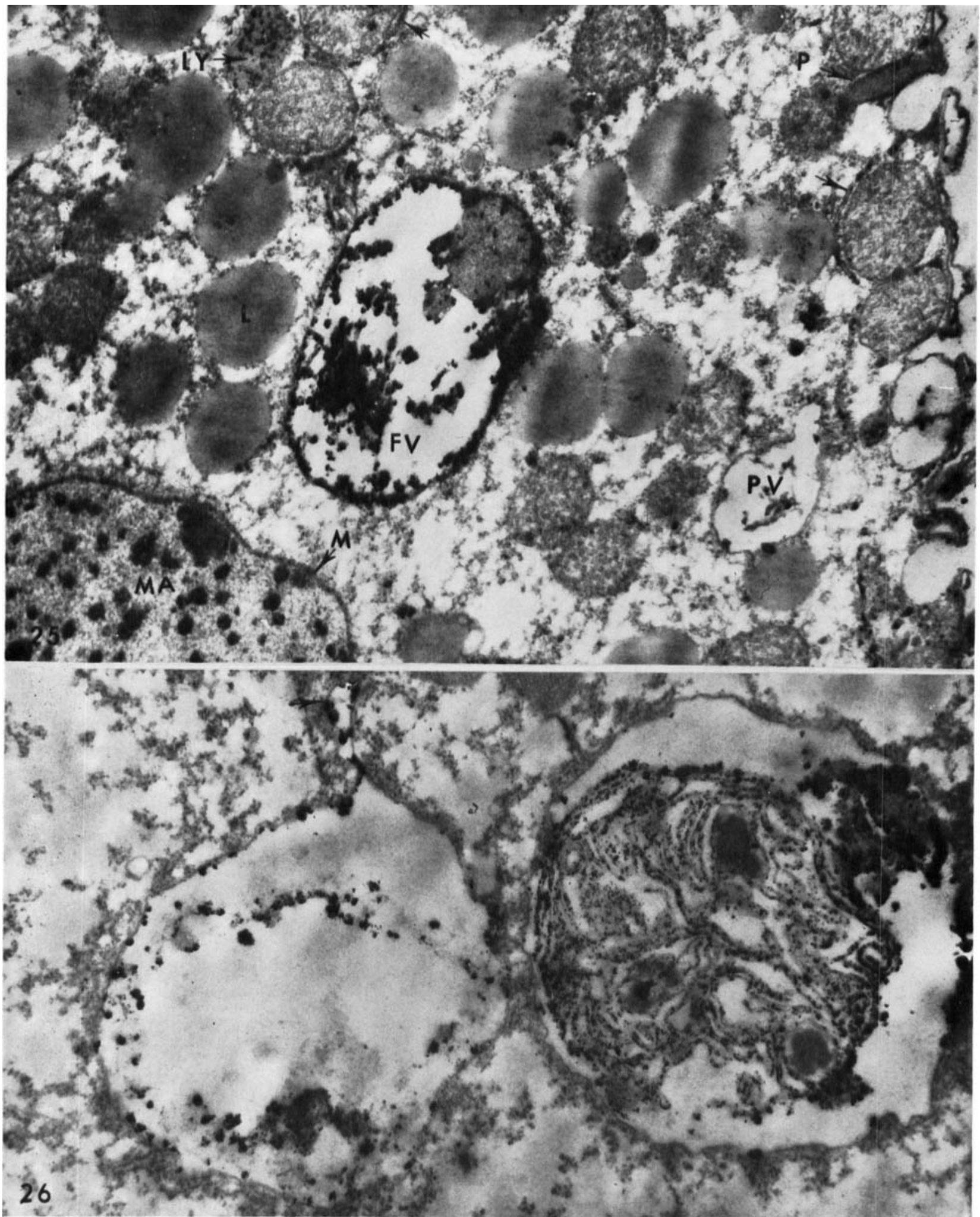

Fig. 25. A low power view of a portion of a ciliate showing reaction products (acid phosphatase) in the lumina of the RER (arrows), primary lysosome (LY), food vacuole (FV), pinocytic vacuole (PV), and perinuclear space of macronuclear membrane (M). The action products in the RER are most dense in that closely associated with mitochondria. The slight reaction in some lipid droplets (L) is probably artifact. The section includes a protricho- cyst (P) and the macronucleus (MA). $\times 9000$.

Fig. 26. Two food vacuoles are shown from a bacteria-fed cell. The one to the right contains partially digested bacteria whereas digestion is completed in the one to the left. Note the finger-like bleb (arrow) suggesting that end products of digestion may leave the vacuole in quantity. $\times 12,000$. 
with the food ingested in the buccal cavity (28). It possesses well-defined structures in the pellicle which have recently been described as remnants of mucocysts following discharge (30). These were previously known by a number of names, one of which was protrichocyst (8). Clear vacuoles are frequently observed near these structures, suggesting that they may arise from them (Figs. 22, 23, 24). The peripherally located pinocytic vacuoles show no acid phosphatase activity. Primary lysosomes are also observed closely associated with pinocytic vacuoles. It is assumed that they coalesce with the pinocytic vacuoles which are then immediately reactive; that is, they contain acid phosphatase. These then join the food vacuoles which also become reactive. Such evidence is seen in many micrographs but, of course, it is only suggestive and does not prove that fusion actually takes place. However, actual fusion of vacu- oles has been observed with the phase-contrast microscope. Since primary lysosomes are also seen in the immediate vicinity of the food vacuoles, it is probable that they unite directly with the vacuole without fusing first with pinocytic vacuoles. The ultimate fate of the food vacuole contents is to gain access to the cytoplasm. This may occur by the extrusion of materials through finger-like projections that pinch off from the food vacuole. Such blebs have been observed in old vacuoles. Jurand(13) suggested that in Paramecium aurelia soluble materials may be transported to the cytoplasm by pinocytosis. Such pinocytic vacuoles are seen in T. pyriformis also (Fig. 11), but these are much smaller than the blebs seen in Fig. 25. Perhaps both processes operate.

The undigested contents of the food vacuoles are discharged from the ciliate through the cytopyge, which un-

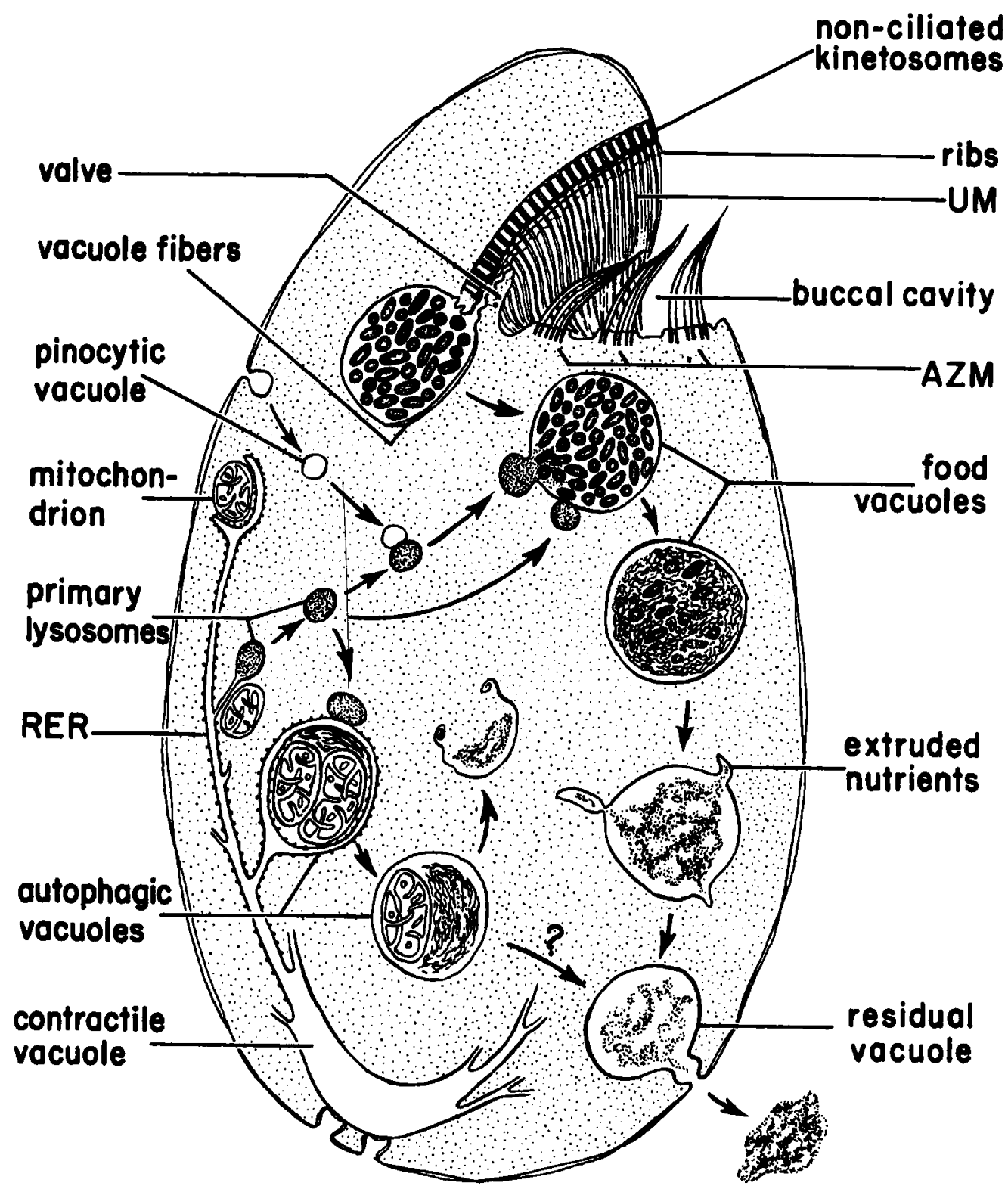

Fig. 27. Schematic representation of the possible structural pathways of intracellular digestion in T. pyriformis. 
fortunately we were never able to identify at the electron microscope level.

In an earlier study(6) we presented ultrastructural evidence for the origin of primary lysosomes from RER in $T$. pyriformis. There is little question about the role of primary lysosomes in digestive events $(4,5,23,24)$. Autophagic vacuoles probably follow stages in degradation similar to those of food vacuoles. They contain acid phosphatase which may have been derived from the RER at the time of their formation or they may acquire it later from primary lysosomes. They may even fuse with pinocytic vacuoles.

The ultimate fate of autophagic vacuoles is conjectural. They may burst and contribute their contents to the cytoplasm of the cell or they may fuse with residual vacuoles (stage IV) and be discharged outside the cell, or they may do both.

The digestive events in $T$. pyriformis have been schematically portrayed in Figure 27 . This sketch is based primarily on information gained from static micrographs and obviously involves considerable speculation. Food vacuoles form below the buccal cavity and move into the cytoplasm. Pinocytic vacuoles may originate from differentiated regions of the pellicle and also move into the cytoplasm. Neither food vacuoles nor pinocytic vacuoles contain hydrolytic enzymes at this early stage. Hydrolases gain entrance to the lumina of the RER and are packaged in primary lysosomes which pinch off from the RER. These coalesce with the pinocytic and the food vacuoles. Once the pinocytic vacuoles receive hydrolases from the primary lysosomes they fuse with the food vacuoles and degradation of the contained food materials is initiated. When digestion is complete, the endproducts are deposited in the cytoplasm, either in massive quantities by means of blebs or by pinocytosis or by both means. Undigested materials are then lost from the cell through the cytopyge. In stationary growth phase cells, autophagic vacuoles appear containing mitochondria and cellular debris. Primary lysosomes may coalesce with them, contributing hydrolases which ultimately digest the contained materials. Autophagic vacuoles may burst when digestion is complete, contributing their contents to the total cellular food reserve. Or they may fuse with residual vacuoles and their contents be egested along with those of the residual vacuoles.

We thank Ann Hunt, Jan Powers. Janis Work and Roger Zieg for technical assistance. We also wish to express our appreciation to Dr. M. Müller for helpful suggestions in the interpretation of our micrographs.

\section{REFERENCES}

1. Allen, S. A., Misch, M. S. \& Morrison, B. M. 1963. Variations in the electrophoretically separated acid phosphatases in Tetrahymena. J. Histochem. Cytochem. 11, 706-19.

2. Carasso, N., Favard, P. \& Goldfischer, S. 1964. Localisation, à l'echelle des ultrastructures, l'activités de phosphatases en rapport avec les processus digestifs chez un cilié (Campanella umbellaria). J. Microscop. 3, 297-322.

3. Corliss, J. O. 1953. Comparative studies on holotrichous ciliates in the Colpidium-Glaucoma-Leucophrys-Tetrahymena group. II. Morphology, life cycles and systematic status of strains in pure cul- ture. Parasitology 43, 49-87.

4. DeDuve, C. 1963. The lysosome concept. In Ciba Foundation Symposium on Lysosomes (A.V.S. de Reuck \& M. P. Cameron, eds.), J. A. Churchill, Ltd., London. 1-35.

5. - 1964. From cytases to lysosomes. Fed. Proc. 23, 1045-49. 6. Elliott, A. M. 1965. Primary lysosomes in Tetrahymena pyriformis. Science 149, 640-1.

7. Elliott, A. M. \& Bak, I. J. 1964. The fate of mitochondria during aging in Tetrahymena pyriformis. J. Cell Biol. 20, 113-30.

8. 1964. The contractile vacuole and related structures in Tetrahymena pyriformis. J. Protozool. 11, 250-61.

9. Furgason, W. H. 1940. The significant cytostomal pattern of the Glaucoma-Colpidium group and a proposed new genus and species, Tetrahymena geleii. Arch. Protistenk. 94, 224-66.

10. Goldfischer, S., Cavasso, N. \& Favard, P. 1963. The demonstration of acid phosphatase activity by electron microscopy in the ergastoplasm of the ciliate Campanella umbellaria. J. Microscop. 2, 621-8.

11. Gomori, G. 1952. Microscopic Histochemistry, Principles and Practice. University of Chicago Press, Chicago.

12. Gordon, G. B., Miller, L. R. \& Bensch, K. G. 1965. Studies on the intracellular digestive process in mammalian tissue culture cells. J. Cell Biol. 25(2), pt. 2, 41-55.

13. Jurand, A. 1961. An electron microscope study of food vacuoles in Paramecium aurelia. J. Protozool, 8, 125-30.

14. Kitching, J. A. 1956. Food vacuoles, Protoplasmatologia III $\mathrm{D} 3 \mathrm{~b}, 1-57$.

15. Klamer, B. \& Fennel, R. 1963. Acid phosphatase activity during growth and synchronous division of Tetrahymena pyriformis $\mathrm{W}$. Exp. Cell Res. 29, 166-75.

16. Luft, J. H. 1961. Improvements in epoxy resin embedding methods. J. Biophysic. Biochem. Cytol. 9, 409-14.

17. Miller, O. L. \& Stone, G. E. 1963. Fine structure of the oral area of Tetrahymena patula. J. Protozool. 10, 280-8.

18. Müller, M. 1962. Studies on feeding and digestion in protozoa. V. Demonstration of some phosphatases and carboxylic esterases in Paramecium multimicronucleatum by histochemical methods. Acta. Biol. Acad. Sci. Hung. 13, 283-97.

19. Müller, M., Röhlich, P., Toth, J. \& Törö, I. 1963. Fine structure and enzymic activity of protozoan food vacuoles. In Ciba Foundation Symposium on Lysosomes (A.V.S. de Reuch \& M. P. Cameron, eds.). J. A. Churchill, Ltd., London, 201-16.

20. Müller, M. \& Röhlich, P. 1961. Studies on feeding and digestion in protozoa. II. Food vacuole cycle in Tetrahymena corlissi. Act. Morphol. Acad. Sci. Hung. 10, 297-305.

21. Müller, M., Röhlich, P. \& Törö, I. 1965. Studies on feeding and digestion in protozoa. VII. Ingestion of polystyrene latex particles and its early effect on acid phosphatase in Paramecium multimicronucleatum and Tetrahymena pyriformis. J. Protozool. 12, 27-34.

22. Müller, M. \& Törö, I. 1962. Studies on feeding and digestion in protozoa. III. Acid phosphatase activity in food vacuoles of Paramecium multimicronucleatum. J. Protozool. 9, 98-102.

23. Novikoff, A. B. 1961. Lysosomes and related particles. In The Cell (J. Brachet and A. Mirsky, eds.). Academic Press, New York.

24. Novikoff, A. B., Essner, E. \& Quintana, N. 1964. The Golgi apparatus and lysosomes. Fed. Proc. 23, 1010-22.

25. Pitelka, D. R. 1963. Electron Microscopic Structure of Protozoa. The Macmillan Co., New York.

26. Schneider, L. 1964. Electronen microskopische Untersuchungen an den Ernährungsorganellen von Paramecium. II. Die Nahrungvakuolen und die Cytopyge. Z. Zellforsch. 62, 225-45.

27. Seaman, G. R. 1961. Acid phosphatase activity associated with phagotrophy in the ciliate, Tetrahymena. J. Biophysic. Biochem. Cytol. 9, 243-5.

28. - 1961. Some aspects of phagotrophy in Tetrahymena. J. Protozool. 8, 204-12.

29. Sommer, J. R. \& Blum, J. 1965. Cytochemical localization of acid phosphatases in Euglena gracilis. J. Cell. Biol. 24, 235-52.

30. Tokuyasu, K. \& Scherbaum, O. H. 1965. Ultrastructure of mucocysts and pellicle of Tetrahymena pyriformis. J. Cell Biol. 27, $67-81$.

31. Weisz, P. 1949. Phosphatases in normal and reorganizing Stentors. Biol. Bull. 97, 108-10.

32. Wichtermann, R. 1953. The Biology of Paramecium. Blakiston Co., New York-Toronto. 